STUDI

FRANCESI

\section{Studi Francesi}

Rivista quadrimestrale fondata da Franco Simone

190 (LXIV | I) | 2020

Varia - fasc. I - gennaio-aprile 2020

\title{
ÉMILE VANDERBURCH, Séliko, ou Le Petit Nègre
}

\section{Amélie Calderone}

\section{OpenEdition \\ Journals}

Édition électronique

URL : https://journals.openedition.org/studifrancesi/22841

DOI : 10.4000/studifrancesi.22841

ISSN : 2421-5856

\section{Éditeur}

Rosenberg \& Sellier

\section{Édition imprimée}

Date de publication : 1 avril 2020

Pagination : 190-191

ISSN : 0039-2944

\section{Référence électronique}

Amélie Calderone, «Émile vanderburch, Séliko, ou Le Petit Nègre », Studi Francesi [En ligne], 190 (LXIV | I) I 2020, mis en ligne le 01 mai 2020, consulté le 03 août 2021. URL : http://journals.openedition.org/ studifrancesi/22841; DOI : https://doi.org/10.4000/studifrancesi.22841

Ce document a été généré automatiquement le 3 août 2021.

\section{(c) (†)}

Studi Francesi è distribuita con Licenza Creative Commons Attribuzione - Non commerciale - Non opere derivate 4.0 Internazionale. 


\title{
ÉMILE VANDERBURCH, Séliko, ou Le Petit Nègre
}

\author{
Amélie Calderone
}

\section{RÉFÉRENCE}

ÉMILE VANDERBURCH, Séliko, ou Le Petit Nègre, suivi de CHARLES SEWRIN, Les Habitants des Landes, édition établie, présentée et annotée par Barbara T. Cooper, Paris, L'Harmattan, 2018, «Autrement Mêmes», 140 pp.

1 Ce volume regroupe deux courtes pièces de théâtre comiques jouées sous l'Empire et la Restauration, Les Habitants des Landes en 1811, et Séliko en 1824. Il appartient à une collection à notre avis trop peu connue, "Autrement Mêmes», attachée à l'édition critique de textes introuvables traitant de l'Autre, en particulier du Noir. Barbara T. Cooper, spécialiste de la question de la représentation des Noirs dans la France du $\mathrm{XIX}^{\mathrm{e}}$ siècle, est une habituée de cette collection à laquelle elle a, à ce jour, offert neuf ouvrages remarquables.

2 L'introduction de l'ouvrage permet au lecteur contemporain de comprendre et de s'approprier ces deux productions dramatiques indissociables du contexte culturel et politique qui les a vues naître. Celles-ci appartiennent au répertoire des petits théâtres parisiens, et sont le fait de deux «grands pourvoyeurs de pièces destinées au Boulevard» (p. VII), Émile Vanderburch et Charles Sewrin. Les Habitants des Landes a été donnée aux Variétés et Séliko a cette particularité d'appartenir au répertoire enfantin, puisque la pièce était destinée au théâtre de M. Comte. Si elles ne valent pas pour leur subtilité poétique, les œuvres sont en revanche cruciales pour comprendre la place qu'occupent les Noirs dans l'imaginaire des Français de l'époque, parce qu'elles mettent toutes deux en scène des héros d'ascendance africaine. Dénonçant l'inégalité des races, elles rappellent combien la question du statut des Noirs a pu poser problème.

Comme le souligne Barbara Cooper, l'une et l'autre partagent un même «cadre géographique "parlant"» (p. VIII), à savoir les environs de Bordeaux, ville portuaire qui 
participe au commerce triangulaire entre Afrique, France et colonies d'Amérique. En cet environnement propice vont pouvoir se rencontrer des gens de différents milieux et cultures. Là s'arrêtent les similitudes, puisque le dessein éducatif et moral de Vanderburch le conduit à produire une pièce «plus grave, [et] plus pathétique» (p. XIII) que son confrère.

4 Avec une minutie qui témoigne de l'étendue de ses compétences en ce domaine, Barbara Cooper met au jour les sources qui ont servi aux deux dramaturges, mais également les œuvres plus ou moins contemporaines traitant de la même thématique et permettant de les mettre en perspective. Vanderburch a ainsi manifestement remanié une nouvelle, Ourika de Mme de Duras (1823), afin de répondre à son ambition éducative: il a masculinisé et rajeuni son héros afin d'écarter la question du mariage interracial, tout en conservant la «réification du personnage africain» (p. xIV). Il a, en outre, évacué le dénouement tragique de sa consœur au profit de «leçons de tolérance et de générosité» prônant l'égalité. À cet égard, il se distingue d'autres auteurs - Mme Leprince de Beaumont ou Mme Jeanne-Sylvie Mallès -, chez lesquels les inégalités demeurent. L'on notera toutefois sa proximité idéologique avec une autre pièce issue du répertoire enfantin, Les Petites Créoles d'Alida de Savignac (1826).

Les Habitants des Landes, quant à elle, "grossit les traits de caractère et de langage» (p. XvIII) qui distinguent les classes et les races - optique comique oblige -, et livre une image «moins ethnographique que conventionnelle et spectaculaire» (p.xIX) des hommes noirs et des Landais. Le rire domine cette petite pièce in fine ambiguë, puisqu'elle permet «au public de sortir du spectacle en se sentant supérieur [...] et persuadé de la suprématie de la "civilisation" française» (p. XXI) - constat que l'on peut rapprocher de certaines pièces inspirées de la venue à Paris, en 1814, de Sarah Bartmann, surnommée la «Vénus Hottentote».

6 Dans un dernier temps de son introduction, Barbara Cooper montre l'accueil réservé aux deux pièces ainsi que leur postérité, grâce à de minutieuses recherches prenant en compte «leur succès au théâtre et leur réception dans la presse, mais aussi leurs éditions et traductions en langues étrangères» (p. XxII): Les Habitants ont ainsi été joués près de 300 fois jusqu'en 1827 à Paris, mais aussi en province, et se sont vus traduits en néerlandais. Si les deux comédies ont peu fait parler d'elles au sein des journaux, les diverses rééditions, jusqu'en 1841, des recueils de Vanderburch intégrant Séliko, montrent a minima la présence de son œuvre dans la culture des jeunes lecteurs, de leurs parents et de leurs précepteurs.

Outre l'introduction et les textes annotés de manière à rendre les comédies intelligibles sans en appesantir la lecture, le volume possède une bibliographie sélective des œuvres des deux dramaturges, et surtout des sources d'époque et des études actuelles sur le sujet, soit autant d'indications qui pourront intéresser les chercheurs dans ce domaine encore à explorer. Enfin, en plus des illustrations dont il est pourvu, l'ouvrage possède des annexes présentant des notices biobibliographiques sur Vanderburch et Sewrin, ainsi que des textes complémentaires entrant en résonnance avec Séliko et Les Habitants des Landes, permettant ainsi de les appréhender dans leur singularité. 